\title{
Prevalence of inappropriate medication using Beers criteria in Japanese long-term care facilities Satoko Niwata*1, Yukari Yamada ${ }^{1,2}$ and Naoki Ikegami ${ }^{1}$
}

Address: ${ }^{1}$ Department of Health Policy and Management, Keio University School of Medicine, Tokyo, Japan and ${ }^{2}$ Department of System Management in Nursing, Graduate School of Health Sciences, Tokyo Medical and Dental University, Tokyo, Japan

Email: Satoko Niwata* - s-niwata@col.hi-ho.ne.jp; Yukari Yamada - yamada-y.kanr@tmd.ac.jp; Naoki Ikegami - ikegami@sc.itc.keio.ac.jp

* Corresponding author

Published: II January 2006

BMC Geriatrics 2006, 6:1 doi:10.1186/147|-2318-6-1
Received: 09 July 2005

Accepted: II January 2006

This article is available from: http://www.biomedcentral.com/I47I-23/8/6/I

(C) 2006 Niwata et al; licensee BioMed Central Ltd.

This is an Open Access article distributed under the terms of the Creative Commons Attribution License (http://creativecommons.org/licenses/by/2.0), which permits unrestricted use, distribution, and reproduction in any medium, provided the original work is properly cited.

\begin{abstract}
Background: The prevalence and risk factors of potentially inappropriate medication use among the elderly patients have been studied in various countries, but because of the difficulty of obtaining data on patient characteristics and medications they have not been studied in Japan.

Methods: We conducted a retrospective cross-sectional study in 17 Japanese long-term care (LTC) facilities by collecting data from the comprehensive MDS assessment forms for 1669 patients aged 65 years and over who were assessed between January and July of 2002. Potentially inappropriate medications were identified on the basis of the 2003 Beers criteria.

Results: The patients in the sample were similar in terms of demographic characteristics to those in the national survey. Our study revealed that $356(21.1 \%)$ of the patients were treated with potentially inappropriate medication independent of disease or condition. The most commonly inappropriately prescribed medication was ticlopidine, which had been prescribed for 107 patients (6.3\%). There were 300 (18.0\%) patients treated with at least I inappropriate medication dependent on the disease or condition. The highest prevalence of inappropriate medication use dependent on the disease or condition was found in patients with chronic constipation. Multiple logistic regression analysis revealed psychotropic drug use $(O R=1.5 \mathrm{II})$, medication cost of per day $(O R=I .173)$, number of medications $(O R=1.140)$, and age $(O R=0.98 \mathrm{I})$ as factors related to inappropriate medication use independent of disease or condition. Neither patient characteristics nor facility characteristics emerged as predictors of inappropriate prescription.
\end{abstract}

Conclusion: The prevalence and predictors of inappropriate medication use in Japanese LTC facilities were similar to those in other countries.

\section{Background}

Inappropriate medication prescription for elderly is a major concern because it increases the risk of adverse events and health care costs [1]. Criteria defining inappropriate medication for the elderly have been developed in order to decrease its occurrence [2-5].
Beers criteria [6-8] have been most widely used to estimate prescription of potentially inappropriate medication for nursing home residents, hospital inpatients, and the community-dwelling elderly in the United States, Canada and European countries [9-47]. However, an extensive literature search did not retrieve any reports on its prevalence 
in Japanese long-term care (LTC) facilities which are of three types: long-term care hospitals (LTCHs), health facilities for the elderly (HFEs), and nursing homes (NHs). The care-mix among LTCHs, HFEs and NHs overlap, but LTCHs tend to care for the severer medical cases, HFEs for light care cases requiring rehabilitation, and NHs for the stable heavy care cases. There is 24 hour physician and nurse coverage in LTCHs, usually 24 hour nurse coverage but only weekday day-time physician coverage in HFEs, and only weekday work hour nurse coverage in $\mathrm{NHs}[48,49]$. Regarding medications, in two of the three types of LTC facilities in Japan, LTCHs and HFEs, the cost of medication is included in the per-diem fee, so the medications prescribed are not listed on the claims forms. In the third, NHs, medication is prescribed by independent physicians and dispensed by free-standing pharmacies. Although it is theoretically possible to obtain data from the claims forms filed by the pharmacies, it has so far not been possible to link the data with the patient assessment data from the NHs. In all three types of facilities, data on diagnosis and functional status at the patient level are very difficult to obtain because there are neither uniform assessment forms nor any formal mechanisms for data collection. As a result, quality monitoring remains focused on only structural aspects, such as staffing, and there is no formal process of pharmacy reviews.
In this study, we focused on the LTC facilities that routinely use the Minimum Data Set (MDS) $[50,51]$ as an assessment instrument for drawing care plans and for monitoring quality. The MDS includes individual patient level information, not only on health or functional status, but also on prescriptions, and has been demonstrated to be highly reliable in the Japanese population [48]. However, the number of LTC facilities that use the MDS are limited, since the form is not mandated in Japan. Therefore, the database we assembled was the only one available for evaluating the prevalence of prescription of potentially inappropriate medication for the elderly in Japanese LTC facilities and analyzing its predictors.

\section{Methods \\ Sample}

This study was conducted in 17 LTC facilities in Japan located throughout the country. We collected the MDS assessment data on 1883 patients aged 65 years and over who were assessed between January and July 2002. Because data on medication prescription for 214 patients were missing, they were excluded. As a result, the database was constructed from the data for the 1669 patients whose data were complete (477 in 8 NHs, 374 in 5 HFEs, and 818 in 4 LTCHs). There were no differences in demographic characteristics (gender, age) between the 1669 subjects of this study and the 214 who were excluded.

Table I: Inappropriate medication criteria excluded from the analysis

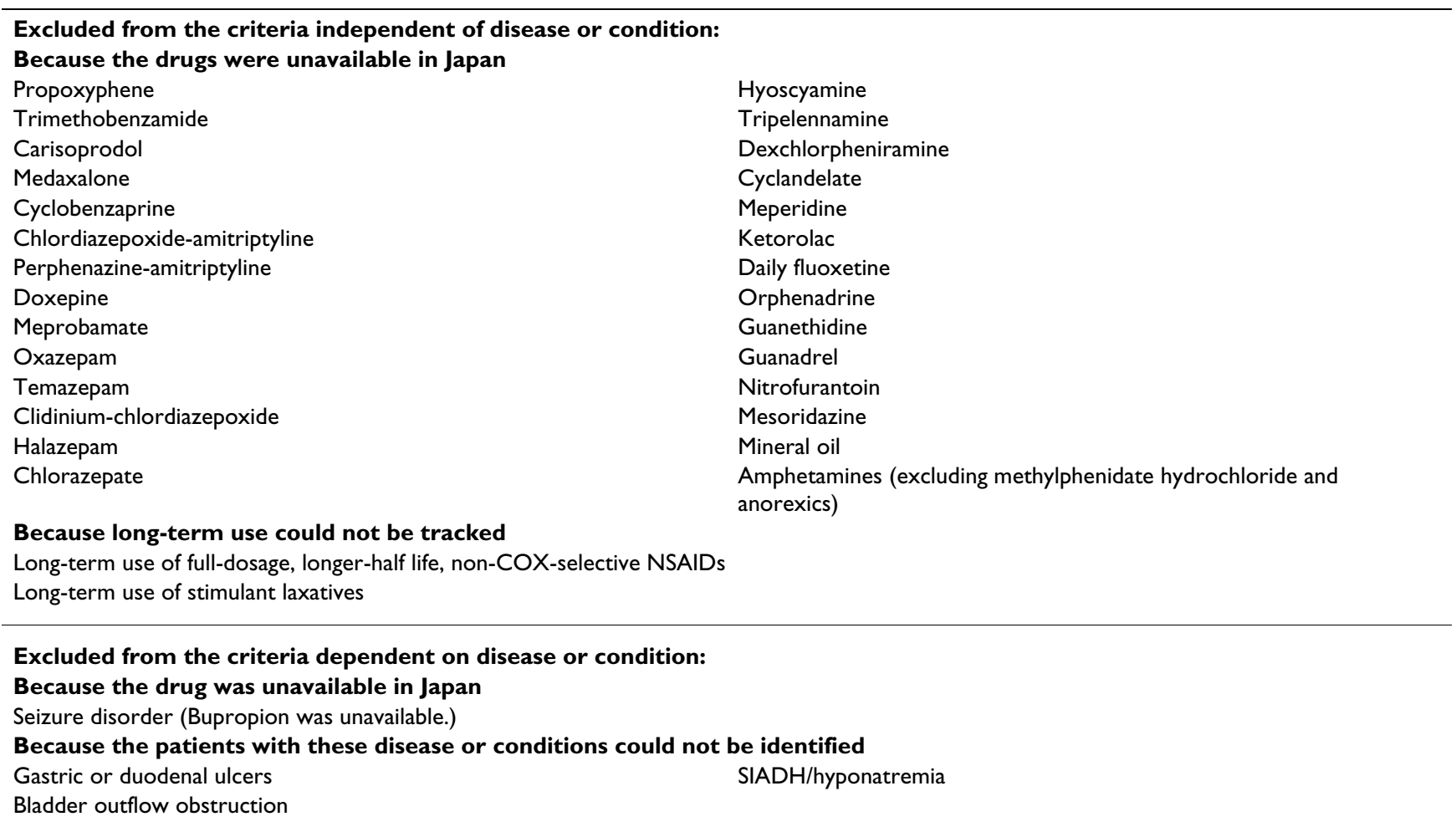


Table 2: Patient characteristics

\begin{tabular}{|c|c|}
\hline Characteristics & $\begin{array}{l}\text { Number of patients as a } \\
\text { percentage of the total } \\
\qquad(N=1669)\end{array}$ \\
\hline \multicolumn{2}{|l|}{ Gender } \\
\hline Male & 25.3 \\
\hline Female & 74.7 \\
\hline \multicolumn{2}{|l|}{ Age } \\
\hline $65-69$ & 3.7 \\
\hline $70-74$ & 7.1 \\
\hline $75-79$ & 13.9 \\
\hline $80-84$ & 22.2 \\
\hline $85-89$ & 24.8 \\
\hline $90-$ & 28.4 \\
\hline Mean age (years) & 84.5 \\
\hline 4 or more diseases & 31.4 \\
\hline ADL score of 2 or more* & 69.1 \\
\hline CPS score of 2 or more ${ }^{* *}$ & 76.3 \\
\hline DRS score of 3 or more ${ }^{* * *}$ & 7.1 \\
\hline \multicolumn{2}{|l|}{ Number of medications } \\
\hline I or more & 94.1 \\
\hline 6 or more & 36.2 \\
\hline 9 or more & 11.9 \\
\hline Psychotropic drug use & 18.6 \\
\hline
\end{tabular}

*ADL: MDS ADL Self-Performance Hierarchy

**CPS: Cognitive Performance Scale

***DRS: Depression Rating Scale

\section{Data collection}

The MDS instrument provides individual level data on the following: background information, such as age, gender, payment source; patient status such as cognitive patterns, physical functioning; and the care provided. Trained staff in each facility filled in the MDS form for each patient by using information obtained through interviews, observations and chart reviews. The MDS also includes detailed information on the medication prescribed during the last 7 days, including the names and doses of the drugs prescribed, their route of administration, and total dosage. A database that included scheduled medication, non-scheduled medication, and PRN medication used at the assessment reference date was constructed. It also included oral medication, external preparations, and injections, but over-the-counter medications were excluded because the data were incomplete.

We also used the MDS ADL Self-Performance Hierarchy in the MDS assessment database, to obtain a composite score for ADL functional status [52]. The scale ranges from 0 (independent) to 6 (total dependence). In this study, a score of 2 (limited impairment) or more were classified as having an ADL disability. Cognitive impairment was assessed by the Cognitive Performance Scale (CPS) [53], which ranges from 0 (intact) to 6 (very severe impair- ment), and a score of 2 (mild impairment) or more were classified as cognitively impaired. Depression was scored by the Depression Rating Scale (DRS) [54], which ranges from 0 to 14 , and a score of 3 or more were classified as depressed as defined by the developers of the scale.

\section{Measurements}

We used the 3rd version of the Beers criteria [8] to identify prescription of potentially inappropriate medication, which are more useful for screening prescriptions that include potentially inappropriate medication than others. We applied the 2003 Beers criteria in this study even though the data were collected in 2002, before the publication of the 2003 version, because we concluded that the differences between the versions would have little impact in Japan since very few physicians are familiar with the Beers criteria and the later version was more comprehensive. We thought that the 2003 version served our purpose of estimating the current prevalence of inappropriate medication use in Japanese LTC facilities based on the current guidelines.

The 2003 Beers criteria consist of 2 lists. One is a list of 49 individual medications or medication classes that are inappropriate for patients 65 years or older regardless of their disease or condition. The other is a list of 56 medications or medication classes in 19 diseases or conditions for which they should be avoided.

In this study, we focused on the 30 medications or medication classes and 15 diseases or conditions. All the medications, medication classes, and diseases or conditions which were excluded from the analysis are indicated in Table 1.

In addition, Beers criteria include medications, such as indomethacin and diphenhydramine, that are frequently used as external preparations in Japan. If limited to external use, the risk of systemic adverse effect should be low. Therefore, we decided to exclude external preparations.

\section{Statistical analysis}

A multiple logistic regression analysis was performed to identify predictors of potentially inappropriate medication use in the patients treated with at least 1 medication. The dependent variable was inappropriate medication use independent of disease or condition. Independent variables were divided into 2 groups. The first group consisted of patient variables, such as age, gender, abnormal laboratory test results in the last 90 days (which were defined as laboratory values that were abnormal when compared to standard values), physical restraint for the last 7 days, ADL disability, cognitive impairment, depression, length of stay, number of diseases, number of medications used per day, medication cost per day, and psychotropic drug use 
Table 3: Prevalence of inappropriate drug prescription (Independent of disease or condition)

\begin{tabular}{llc}
\hline \multicolumn{1}{c}{ Drugs } & Severity* & Number of patients as a percentage of total \\
& & $(\mathrm{N}=1669)$ \\
\hline Pentazocine & High & 0.2 \\
Muscle relaxants and antispasmodics & High & 0.9 \\
Amitriptyline & High & 0.0 \\
Long-acting benzodiazepines & High & 1.9 \\
Disopyramide & High & 0.2 \\
Digoxin >0.125 mg/d & Low & 0.0 \\
Short-acting dipyridamole & Low & 0.0 \\
Gastrointestinal antispasmodic drugs & High & 0.1 \\
Anticholinergics and antihistamines & High & 1.4 \\
Ferrous sulfate>325 mg/d & Low & 0.2 \\
Ticlopidine & High & 6.3 \\
Doxazosin & Low & 1.5 \\
Thioridazine & High & 0.1 \\
Short-acting nifedipine & High & 2.0 \\
Cimetidine & Low & 1.5 \\
Indomethacin & High & 0.1 \\
Desiccated thyroid & High & 0.1 \\
Methyldopa & High & 0.1 \\
Use of any inappropriate drugs & & 21.1
\end{tabular}

* Severity: Defined conceptually as a combination of both the likelihood that an adverse outcome would occur and the clinical significance of that outcome should it occur [7].

(as defined by the Narcotics and Psychotropics Control Law in Japan). The second group consisted of facility variables and were facility type, method of reimbursement for the cost of medication, and the number of beds in the facility. Medication cost per day was converted to natural logs because it had a long-tail distribution. All variables were entered into the multiple logistic regression model by the backward stepwise method. Data were analyzed by using SPSS 12.0J software for Windows.

\section{Results}

The demographic characteristics of the population studied are listed in Table 2. Their gender and ages were similar to data in a national survey of the same period [55].

Of the 1669 patients, $356(21.1 \%)$ were treated with at least 1 potentially inappropriate medication independent of the disease or condition in 2003 Beers criteria, and 308 $(86.5 \%)$ of them treated with 1 medication on the list, 41 $(11.5 \%)$ with 2 , and $7(2.0 \%)$ with 3 . Table 3 shows the prevalence of prescription of each medication or medication class. The most commonly used inappropriate medication was ticlopidine, which was used by 107 patients $(6.3 \%)$.

There were 300 patients (18.0\%) who met the criteria for potentially inappropriate medication dependent on disease or condition. $244(81.3 \%)$ of them were treated with 1 medication on the list, $51(17.0 \%)$ with $2,3(1.0 \%)$ with 3 , and $2(0.7 \%)$ with 4 . Table 4 shows the prevalence of potentially inappropriate medication use dependent on disease or condition. The highest prevalence of inappropriate medication use was for 165 among 548 patients with chronic constipation, who were prescribed inappropriate medications, such as calcium channel blockers, anticholinergics, and tricyclic antidepressants.

Table 5 shows the results of the multiple logistic regression analysis to identify predictors of inappropriate medication use, independent of disease or condition. Psychotropic drug use $(\mathrm{OR}=1.511)$, medication cost per day $(\mathrm{OR}=1.173)$ and the number of medications used per day $(\mathrm{OR}=1.140)$ increased the risk of inappropriate medication use, while age $(\mathrm{OR}=0.981)$ decreased the risk.

\section{Discussion \\ Prevalence of potentially inappropriate medication use independent of disease or condition}

The prevalence of prescription of potentially inappropriate medication based on the 2003 Beers criteria were $13.4 \%$ in the United States [46], and 5.8 to $25.7 \%$ in 8 European countries [42]. On earlier versions of the criteria, they were 10.5 to $54.7 \%$ in patients in nursing homes $[9,14,21,26,27,29,30,33,39]$ and 2.2 to $35.6 \%$ in patients in the community $[10-12,16-18,20-25,28,31,32,34$ $37,40-46]$. The prevalence in this study was essentially the same. Parenthetically, there were $5(0.2 \%)$ terminally ill patients in the sample but inappropriate medication was not prescribed for this group. 
Table 4: Prevalence of inappropriate drug prescription (Dependent on disease or condition)

\begin{tabular}{|c|c|c|c|c|}
\hline Disease or condition & Drug & Severity & $\mathrm{n} / \mathrm{N} *$ & $\%$ \\
\hline Heart failure & Disopyramide, high sodium content drugs & High & $4 / 114$ & 3.5 \\
\hline Seizures or epilepsy & Chlorpromazine, thioridazine & High & $2 / 57$ & 3.5 \\
\hline $\begin{array}{l}\text { Blood clotting disorders or } \\
\text { receiving anticoagulant therapy }\end{array}$ & Aspirin, NSAIDs, dipyridamole, ticlopidine & High & $4 / 27$ & 14.8 \\
\hline Stress incontinence $* *$ & $\alpha$-Blockers, anticholinergics, tricyclic antidepressants, long-acting benzodiazepines & High & $89 / 1028$ & 8.7 \\
\hline Arrhythmias & Tricyclic antidepressants & High & $1 / 106$ & 0.9 \\
\hline Insomnia & Decongestants, theophylline, methylphenidate, MAOI, amphetamines & High & $4 / 92$ & 4.3 \\
\hline Parkinson's disease & Metoclopramide, conventional antipsychotics & High & $19 / 88$ & 11.4 \\
\hline Cognitive impairment & Barbiturates, anticholinergics, antispasmodics, muscle relaxants, CNS stimulants & High & $52 / 1273$ & 4.I \\
\hline Depression & Sympatholytic agents & High & $8 / 119$ & 6.7 \\
\hline Syncope or falls & Short to intermediate-acting benzodiazepine, tricyclic antidepressants & High & $23 / 103$ & 22.3 \\
\hline COPD & Long-acting benzodiazepines, $\beta$-blockers & High & $1 / 44$ & 2.3 \\
\hline Chronic constipation & Calcium channel blockers, anticholinergics, tricyclic antidepressants & Low & $165 / 548$ & 30.1 \\
\hline \multicolumn{3}{|c|}{ Use of any of above for each disease or condition } & $300 / 1669$ & 18.0 \\
\hline
\end{tabular}

* N: Number of patients with the disease or condition. $\mathrm{n}$ : Number of patients treated with any of drug(s) that are inappropriate for that disease or condition.

** We could not identify the patients with 'stress incontinence' because the MDS data were limited to 'incontinence' in general.

The most commonly inappropriately prescribed medication was ticlopidine. By contrast, ticlopidine is rarely used in the United States, because clopidogrel, a safer alternative to aspirin, is available. However, clopidogrel was not available in Japan at the time of the study, which may have led to a higher prevalence of inappropriate use than would have been the case if it had been available. The fact that ticlopidine was also commonly prescribed in Italy $[30,42]$, where clopidogrel was also unavailable, may provide support for this hypothesis. When ticlopidine was excluded from the list, the prevalence of potentially inappropriate medication use independent of the disease or condition decreased from $21.1 \%$ to $16.4 \%$, thus remaining in the range of previous studies.

Anticholinergics and antihistamines, long-acting benzodiazepines, short-acting dipyridamole, and short-acting nifedipine were other medications on the list that were frequently used. The prevalence of inappropriate prescription of dipyridamole and nifedipine use in this study was slightly higher than in other studies. Propoxyphene was commonly used in the United States, but was not prescribed for the subjects of this study because it was unavailable in Japan. The prevalence of the antiarrhythmic agent, amiodarone, added to the 2003 Beers criteria, was also high in previous studies $[42,46]$, but none of the patient were treated with it in our study because the national formulary regulation in Japan restricts its use to cases in which other medications have proved ineffective.

\section{Factors associated with inappropriate medication use independent of the disease or condition}

The result of the multiple logistic regression analysis in this study identified psychotropic drug use, number of medications per day, medication cost per day, and age as factors associated with inappropriate medication prescription in LTC facilities, which was the same as in other countries $\quad[9,10,15,18,19,21,25-32,35-39,42,43,46]$. When ticlopidine was excluded from the analysis, the results did not change greatly, but age and cost of medication per-day were excluded.

It should be noted that the other patient variables and the 3 facility variables were not selected in the multiple logistic regression analysis. Since Japanese LTC facilities differ not only in professional staffing levels and medical need, but in reimbursement for medication costs, we expected these characteristics to be reflected in the prescription pat-

Table 5: Multiple logistic regression analysis to identify predictors of inappropriate drug use

\begin{tabular}{|c|c|c|c|c|}
\hline Variable & Odds ratio & $95 \% \mathrm{Cl}$ & $P$ value & Correlation coefficient* \\
\hline Psychotropic drug use & 1.528 & $1.133-2.059$ & 0.005 & 0.156 \\
\hline Medication cost per day** & 1.172 & $1.011-1.360$ & 0.036 & 0.213 \\
\hline $\begin{array}{l}\text { Number of medications } \\
\text { per day }\end{array}$ & 1.141 & $1.075-1.211$ & 0.000 & 0.268 \\
\hline Age & $0.98 \mathrm{I}$ & $0.965-0.998$ & 0.029 & -0.124 \\
\hline
\end{tabular}

* The Pearson's bivariate correlation coefficients.

** Cost of medication per day has been converted to natural logs. 
tern. The fact that these variables were not included indicates that the prescription pattern in Japanese LTC facilities depends on other factors, such as the prescribing habits of individual physicians.

\section{Limitations}

The first limitation of this study is that the sample facilities in this study may have been of higher quality, both in the standard of care and prescribing habits, which would lead to a lower prevalence of inappropriate medication prescription. Second, many have noted that the Beers criteria do not include drug-drug interactions or underprescribing $[10,11,27,29,30,35,40,46]$. Third, there may be racial differences in some drugs metabolizing enzymes $[56,57]$ that affect the incidence of adverse effects as well as the dosage limitations on the list. Finally, there may be potentially inappropriate medications for elderly that are available in Japan but not in the United States, and if there are, modifications of the Beers criteria based on expert opinion would be needed for application to Japan. However, the Japan Geriatrics Society had just published guidelines for appropriate medication prescription for the elderly when this paper was submitted [58]. They are a modification of the 2003 Beers criteria, and the majority of the guidelines appear to follow the original criteria with some changes in dose and the addition of several medications. Thus, although we used the original Beers criteria to make our study comparable to international studies, our results appear to be generally applicable to the Japanese situation.

\section{Conclusion}

By focusing on LTC facilities that used the MDS comprehensive assessment form, we were able to confirm for the first time that the prevalence of inappropriate medication prescription in Japanese LTC facilities was $21 \%$ according to the criteria independent of disease or condition and $18 \%$ according to the criteria dependent on disease or condition, based on the 2003 Beers criteria. The results of a multiple logistic regression analysis indicated that psychotropic drug use and the number of medications prescribed per day are risk factors of potentially inappropriate medication use independent of disease or condition. These results are similar to those of previous studies in other countries.

\section{Competing interests}

The author(s) declare that they have no competing interests.

\section{Authors' contributions}

SN constructed the database, performed the statistical analysis, and drafted the manuscript. YY assisted in performing the analysis and drafting the manuscript. NI conceived the study design, obtained the data, and assisted in drafting the manuscript. All authors read and approved the final manuscript.

\section{Acknowledgements}

This study was sponsored by The National Federation of Health Insurance Societies. The authors would like to thank the fellows of the inter RAI for their valuable comments.

\section{References}

I. Bootman JL, Harrison DL, Cox E: The health care cost of drugrelated morbidity and mortality in nursing facilities. Arch Intern Med 1997, 157:2089-2096.

2. McLeod PJ, Huang AR, Tamblyn RM, Gayton DC: Defining inappropriate practices in prescribing for elderly people: a national consensus panel. CMAJ 1997, I56:385-391.

3. Oborne CA, Batty GM, Maskrey V, Swift CG, Jackson SH: Development of prescribing indicators for elderly medical inpatients. Br J Clin Pharmacol 1997, 43:91-97.

4. Brown NJ, Griffin MR, Ray WA, Meredith S, Beers MH, Marren J, Robles M, Stergachis A, Wood AJ, Avorn J: A model for improving medication use in home health care patients. J Am Pharm Assoc (Wash) 1998, 38:696-702.

5. Hanlon JT, Schmader KE, Boult C, Artz MB, Gross CR, Fillenbaum GG, Ruby CM, Garrard J: Use of inappropriate prescription drugs by older people. J Am Geriatr Soc 2002, 50:26-34.

6. Beers MH, Ouslander JG, Rollingher I, Reuben DB, Brooks J, Beck JC: Explicit criteria for determining inappropriate medication use in nursing home residents. UCLA Division of Geriatric Medicine. Arch Intern Med 1991, I51:1825-1832.

7. Beers $\mathrm{MH}$ : Explicit criteria for determining potentially inappropriate medication use by the elderly. An update. Arch Intern Med 1997, 13:|53I-1536.

8. Fick DM, Cooper JW, Wade WE, Waller JL, Maclean JR, Beers MH: Updating the Beers criteria for potentially inappropriate medication use in older adults: results of a US consensus panel of experts. Arch Intern Med 2003, 59:2716-2724.

9. Beers MH, Ouslander JG, Fingold SF, Morgenstern H, Reuben DB, Rogers W, Zeffren MJ, Beck JC: Inappropriate medication prescribing in skilled-nursing facilities. Ann Intern Med 1992, I 1 7:684-689.

10. Stuck AE, Beers MH, Steiner A, Aronow HU, Rubenstein LZ, Beck JC: Inappropriate medication use in community-residing older persons. Arch Intern Med 1994, 1 54:21 95-2200.

II. Willcox SM, Himmelstein DU, Woolhandler S: Inappropriate drug prescribing for the community-dwelling elderly. JAMA 1994, 272:292-296.

12. Gupta S, Rappaport HM, Bennett LT: Inappropriate drug prescribing and related outcomes for elderly medicaid beneficiaries residing in nursing homes. Clin Ther 1996, 18:183-196.

13. Aparasu RR, Fliginger SE: Inappropriate medication prescribing for the elderly by office-based physicians. Ann Pharmacother 1997, 31:823-829.

14. Spore DL, Mor V, Larrat P, Hawes C, Hiris J: Inappropriate drug prescriptions for elderly residents of board and care facilities. Am J Public Health 1997, 87:404-409.

15. Aparasu RR, Sitzman S): Inappropriate prescribing for elderly outpatients. Am J Health Syst Pharm 1999, 56:433-439.

16. Chin MH, Wang LC, Jin L, Mulliken R, Walter J, Hayley DC, Karrison TG, Nerney MP, Miller A, Friedmann PD: Appropriateness of medication selection for older persons in an urban academic emergency department. Acad Emerg Med 1999, 6:1232-1242.

17. Golden AG, Preston RA, Barnett SD, Llorente M, Hamdan K, Silverman MA: Inappropriate medication prescribing in homebound older adults. J Am Geriatr Soc 1999, 47:948-953.

18. Hanlon JT, Fillenbaum GG, Schmader KE, Kuchibhatla M, Horner RD Inappropriate drug use among community-dwelling elderly. Pharmacotherapy 2000, 20:575-582.

19. Mort JR, Aparasu RR: Prescribing potentially inappropriate psychotropic medications to the ambulatory elderly. Arch Intern Med 2000, 160:2825-2831.

20. Mott DA, Meek PD: Evaluating prescriptions for the elderly: drug/age criteria as a tool to help community pharmacists. $j$ Am Pharm Assoc (Wash) 2000, 40:4I7-424. 
21. Piecoro LT, Browning SR, Prince TS, Ranz TT, Scutchfield FD: A database analysis of potentially inappropriate drug use in an elderly medicaid population. Pharmacotherapy 2000, 20:22I-228.

22. Fick DM, Waller JL, Maclean JR, Heuvel RV, Tadlock JG, Gottlieb M, Cangialose CB: Potentially Inappropriate Medication Use in a Medicare Managed Care Population: Association with Higher Costs and Utilization. J Manage Care Pharm 200I, 7:407-4I3

23. Meredith S, Feldman PH, Frey D, Hall K, Arnold K, Brown NJ, Ray WA: Possible medication errors in home healthcare patients. J Am Geriatr Soc 200I, 49:719-724.

24. Spiker EC, Emptage RE, Giannamore MR, Pedersen CA: Potentia adverse drug events in an indigent and homeless geriatric population. Ann Pharmacother 2001, 35:1166-1172.

25. Zhan C, Sangl J, Bierman AS, Miller MR, Friedman B, Wickizer SW, Meyer GS: Potentially inappropriate medication use in the community-dwelling elderly: findings from the 1996 Medical Expenditure Panel Survey. JAMA 200I, 286:2823-2829.

26. Dhall J, Larrat EP, Lapane KL: Use of potentially inappropriate drugs in nursing homes. Pharmacotherapy 2002, 22:88-96.

27. Dhalla IA, Anderson GM, Mamdani MM, Bronskill SE, Sykora K, Rochon PA: Inappropriate prescribing before and after nursing home admission. I Am Geriatr Soc 2002, 50:995-1000.

28. Pitkala KH, Strandberg TE, Tilvis RS: Inappropriate drug prescribing in home-dwelling, elderly patients: a population-based survey. Arch Intern Med 2002, 162:1707-17/2.

29. Sloane PD, Zimmerman S, Brown LC, Ives TJ, Walsh JF: Inappropriate medication prescribing in residential care/assisted living facilities. J Am Geriatr Soc 2002, 50:I00 I-I0II.

30. Onder G, Landi F, Cesari M, Gambassi G, Carbonin P, Bernabei R: Inappropriate medication use among hospitalized older adults in Italy: results from the Italian Group of Pharmacoepidemiology in the Elderly. Eur J Clin Pharmacol 2003, 59:157-162.

3I. Stuart B, Kamal-Bahl S, Briesacher B, Lee E, Doshi J, Zuckerman IH, Verovsky I, Beers MH, Erwin G, Friedley N: Trends in the prescription of inappropriate drugs for the elderly between 1995 and 1999. Am J Geriatr Pharmacother 2003, I:61-74

32. Caterino JM, Emond JA, Camargo CA Jr: Inappropriate medication administration to the acutely ill elderly: a nationwide emergency department study, 1992-2000. J Am Geriatr Soc 2004, 52: I847-1855.

33. Chang CM, Liu PY, Yang YH, Yang YC, Wu CF, Lu FH: Potentially inappropriate drug prescribing among first-visit elderly outpatients in Taiwan. Pharmacotherapy 2004, 24:848-855.

34. Curtis LH, Ostbye T, Sendersky V, Hutchison S, Dans PE, Wright A, Woosley RL, Schulman KA: Inappropriate prescribing for elderly Americans in a large outpatient population. Arch Intern Med 2004, 164:1621-1625.

35. Goulding MR: Inappropriate medication prescribing for elderly ambulatory care patients. Arch Intern Med 2004, 164:305-3/2.

36. Howard M, Dolovich L, Kaczorowski J, Sellors C, Sellors J: Prescribing of potentially inappropriate medications to elderly people. Fam Pract 2004, 2 1:244-247.

37. Lane CI, Bronskill SE, Sykora K, Dhalla IA, Anderson GM, Mamdani MM, Gill SS, Gurwitz JH, Rochon PA: Potentially inappropriate prescribing in Ontario community-dwelling older adults and nursing home residents. I Am Geriatr Soc 2004, 52:86I-866.

38. Oster G, Berger A, Dukes E, Edelsberg J, McCarberg B: Use of potentially inappropriate pain-related medications in older adults with painful neuropathic disorders. Am J Geriatr Pharmacother 2004, 2:163-170.

39. Rancourt C, Moisan J, Baillargeon L, Verreault R, Laurin D, Gregoire JP: Potentially inappropriate prescriptions for older patients in long-term care. BMC Geriatr 2004, 4:9.

40. Vlahovic-Palcevski V, Bergman U: Quality of prescribing for the elderly in Croatia-computerized pharmacy data can be used to screen for potentially inappropriate prescribing. Eur J Clin Pharmacol 2004, 60:217-220.

4I. Ay P, Akici A, Harmanc H: Drug utilization and potentially inappropriate drug use in elderly residents of a community in Istanbul, Turkey. Int / Clin Pharmacol Ther 2005, 43:195-202

42. Fialova D, Topinkova E, Gambassi G, Finne-Soveri H, Jonsson PV, Carpenter I, Schroll M, Onder G, Sorbye LW, Wagner C, Reissigova J, Bernabei R: Potentially inappropriate medication use among elderly home care patients in Europe. JAMA 2005, 293:1348-1358.

43. Lechevallier-Michel N, Gautier-Bertrand M, Alperovitch A, Berr C, Belmin J, Legrain S, Saint-Jean O, Tavernier B, Dartigues JF, FourrierReglat A: Frequency and risk factors of potentially inappropriate medication use in a community-dwelling elderly population: results from the 3C Study. Eur I Clin Pharmacol 2005, 60:813-819.

44. Rigler SK, Jachna CM, Perera S, Shireman TI, Eng ML: Patterns of potentially inappropriate medication use across three cohorts of older medicaid recipients. Ann Pharmacother 2005, 39: $1175-1181$.

45. Simon SR, Chan KA, Soumerai SB, Wagner AK, Andrade SE, Feldstein AC, Lafata JE, Davis RL, Gurwitz JH: Potentially inappropriate medication use by elderly persons in U.S. Health Maintenance Organizations, 2000-200I. J Am Geriatr Soc 2005, 53:227-232.

46. Viswanathan $\mathrm{H}$, Bharmal M, Thomas 3: Prevalence and correlates of potentially inappropriate prescribing among ambulatory older patients in the year 200I: comparison of three explicit criteria. Clin Ther 2005, 27:88-99.

47. Zhan C, Correa-de-Araujo R, Bierman AS, Sangl J, Miller MR, Wickizer SW, Stryer D: Suboptimal prescribing in elderly outpatients: potentially harmful drug-drug and drug-disease combinations. J Am Geriatr Soc 2005, 53:262-267.

48. Ikegami N, Fries BE, Takagi Y, Ikeda S, Ibe T: Applying RUG-III in Japanese long-term care facilities. Gerontologist 1994, 34:628-639.

49. Ikegami N, Yamauchi K, Yamada Y: The long term care insurance law in Japan: impact on institutional care facilities. Int $J$ Geriatr Psychiatry 2003, I 8:217-22I.

50. Morris JN, Murphy K, Nonemaker S, (Eds): Long Term Care Resident Assessment Instrument User's Manual for Version 2.0 Baltimore: Health Care Financing Administration; 1995.

5I. Morris JN, Murphy K, Nonemaker S, (Eds): (Ikegami N. translated) Long Term Care Resident Assessment Instrument User's Manual for Version 2.I Tokyo: Igaku Shoin; 2005.

52. Morris JN, Fries BE, Morris SA: Scaling ADLs within the MDS. J Gerontol A Biol Sci Med Sci 1999, 54:M546-M553.

53. Morris JN, Fries BE, Mehr DR, Hawes C, Phillips C, Mor V, Lipsitz LA MDS Cognitive Performance Scale. I Gerontol 1994, 49:MI74-MI82.

54. Burrows AB, Morris JN, Simon SE, Hirdes JP, Phillips C: Development of a minimum data set-based depression rating scale for use in nursing homes. Age Ageing 2000, 29:165-172.

55. Ministry of Health, Labour and Welfare Minister's Secretariat Statistics and Information Dept. (Ed): Survey on Long-term Care Insurance Facilities and Long-term Care Services Providing Companies 200I Tokyo: Health \& Welfare Statistics Association; 2003.

56. Nasu K, Kubota T, Ishizaki T: Genetic analysis of CYP2C9 polymorphism in a Japanese population. Pharmacogenetics 1997, 7:405-409.

57. Nishida Y, Fukuda T, Yamamoto I, Azuma J: CYP2D6 genotypes in a Japanese population: low frequencies of CYP2D6 gene duplication but high frequency of CYP2D6*10. Pharmacogenetics 2000, 10:567-570.

58. The Japan Geriatrics Society (Ed): Koureisha no anzen na yakubutsu ryouhou gaidorain 2005 [Guidelines for medical treatment and its safety in the elderly] Tokyo: Medical View Co., Ltd; 2005.

\section{Pre-publication history}

The pre-publication history for this paper can be accessed here:

http://www.biomedcentral.com/1471-2318/6/1/prepub 